\title{
Histone methyltransferase activity associated with a human multiprotein complex containing the Enhancer of Zeste protein
}

\author{
Andrei Kuzmichev, ${ }^{1}$ Kenichi Nishioka, ${ }^{1}$ Hediye Erdjument-Bromage, ${ }^{2}$ Paul Tempst, ${ }^{2}$ \\ and Danny Reinberg ${ }^{1,3}$ \\ ${ }^{1}$ Howard Hughes Medical Institute, Division of Nucleic Acids Enzymology, Department of Biochemistry, University \\ of Medicine and Dentistry of New Jersey, Robert Wood Johnson Medical School, Piscataway, New Jersey 08854, USA; \\ ${ }^{2}$ Molecular Biology Program, Memorial Sloan Kettering Cancer Center, New York, New York 10021, USA
}

\begin{abstract}
Enhancer of Zeste $[\mathrm{E}(\mathrm{z})]$ is a Polycomb-group transcriptional repressor and one of the founding members of the family of SET domain-containing proteins. Several SET-domain proteins possess intrinsic histone methyltransferase (HMT) activity. However, recombinant $E(z)$ protein was found to be inactive in a $H M T$ assay. Here we report the isolation of a multiprotein $\mathrm{E}(\mathrm{z})$ complex that contains extra sex combs, suppressor of zeste-12 [Su(z)12], and the histone binding proteins $\mathrm{RbAp46/RbAp48.} \mathrm{This} \mathrm{complex,} \mathrm{which} \mathrm{we} \mathrm{termed}$ Polycomb repressive complex (PRC) 2, possesses HMT activity with specificity for Lys 9 (K9) and Lys 27 (K27) of histone H3. The HMT activity of PRC2 is dependent on an intact SET domain in the E(z) protein. We hypothesize that transcriptional repression by the $\mathrm{E}(\mathrm{z})$ protein involves methylation-dependent recruitment of PRC1. The presence of $\mathrm{Su}(\mathrm{z}) 12$, a strong suppressor of position effect variegation, in PRC2 suggests that PRC2 may play a widespread role in heterochromatin-mediated silencing.
\end{abstract}

[Keywords: Histone methylation; Polycomb; SET domain; transcription repression; chromatin]

Received August 23, 2002; revised version accepted September 23, 2002.

The Polycomb group (PcG) proteins were first identified in the fruit fly Drosophila melanogaster (for review, see Jacobs and van Lohuizen 1999). These proteins are required for long-term transcriptional silencing of the Drosophila homeotic genes, which are required for proper embryonic development. The mechanism by which PcG proteins repress transcription is largely unknown; however, these proteins are known to be present in multiprotein complexes. The best characterized complex is Polycomb repressive complex (PRC) 1, which contains the Polycomb, Polycomb-like, Polyhomeotic, Posterior Sex Combs, and Sex Combs on Midleg proteins, among others (Shao et al. 1999). Interaction of PRC1 with a chromatin template renders it resistant to remodeling by the chromatin remodeling complex Brahma.

Another PcG protein complex, which is distinct from PRC1, contains at least the Enhancer of Zeste $[\mathrm{E}(z)]$ and Extra Sex Combs (ESC) proteins. This complex has an apparent molecular size of $\sim 400 \mathrm{kD}$, and its complete composition is unknown (Sewalt et al. 1998; $\mathrm{Ng}$ et al. 2000; Tie et al. 2001). The mechanism of transcriptional

${ }^{3}$ Corresponding author.

E-MAIL reinbedf@umdnj.edu; FAX (732) 235-5294.

Article and publication are at http://www.genesdev.org/cgi/doi/10.1101/ gad.1035902. repression by the ESC-E $(z)$ complex has not yet been established, but it has been proposed that the process involves interaction of the complex with histone deacetylases (van der Vlag and Otte, 1999; Tie et al. 2001). Genetic studies suggest that transcriptional repression can be achieved by a mechanism that involves ESC-E(z)-directed recruitment of the PRC1 repressive complex to chromosomes via the chromodomain of Polycomb (Rastelli et al. 1993; Platero et al. 1996). This recruitment might be dependent on chromatin modification that creates a binding site for the $\mathrm{PRC} 1$ repressive complex by ESC-E $(z)$.

Position effect variegation (PEV) is the result of heterochromatin-mediated transcriptional silencing, a process that is distinct from PcG repression of gene expression. PEV is the clonally variegated expression of a reporter gene placed near a heterochromatin boundary (for review, see Jacobs and van Lohuizen 1999). Overexpression of mammalian or Drosophila E(z) can enhance PEV of the heterochromatin-associated white gene (Laible et al. 1997). Another notable example of a PcG gene that can affect PEV in Drosophila is the recently identified gene Suppressor of Zeste-12 [Su(z)12; Birve et al. 2001]. The $\operatorname{Su}(z) 12$ gene shares striking functional similarity with $\mathrm{E}(\mathrm{z})$. Flies that are homozygous for strong loss-offunction alleles of $\operatorname{Su}(z) 12$ die as early embryos, whereas 
heterozygous flies carrying one wild-type $\operatorname{Su}(z) 12$ and one leaky $\operatorname{Su}(z) 12$ mutant allele display suppression of PEV and misexpression of the HOX genes (Birve et al. 2001). These findings illustrate that $\operatorname{Su}(z) 12$ has dual functions, one similar to that of the PcG proteins and another that mimics the function of genes that suppress PEV [Su(var)]. Recently, a human homolog of Su(z)12 was identified by two independent approaches: as a translocation in benign endothelial stromal tumors (Koontz et al. 2001) and as a gene that is regulated by the E2F4 transcriptional activator protein (Weinmann et al. 2001).

$\mathrm{E}(z)$ is one of the founding members of the SET [ $\underline{\mathrm{Su}}$ (var)3-9; E $(z)$; Trithorax] domain family of proteins. Recently, SET domains within several proteins-including the mammalian proteins SUV39H (Rea et al. 2000), G9A (Tachibana et al. 2001), ESET (Yang et al. 2002), Set9 (Nishioka et al. 2002a; Wang et al. 2001a), and PR-Set7 (Nishioka et al. 2002b), and the yeast proteins Set1 (Briggs et al. 2001) and Set2 (Strahl et al. 2002)-were shown to possess lysine-specific HMT activity. We tested whether transcriptional repression by the human $\mathrm{E}(z)$ protein involves a HMT activity. To this end, we isolated a native human $\mathrm{E}(\mathrm{z})$ complex and demonstrated in the present studies that this complex contains the human homologs of the ESC and Su(z)12 proteins, as well as the histone binding proteins RbAp46 and RbAp48. We termed this complex PRC2. PRC2 possesses HMT activity with specificity for K9 and K27 of histone H3. Taken together, our findings provide a unified explanation for the diverse functions of the $\mathrm{E}(\mathrm{z})$ protein.

\section{Results}

Isolation of a human E(z)-ESC complex

The presence of a SET domain within E(z), together with its associated repressive function, strongly suggests that the $\mathrm{E}(\mathrm{z})$ protein possesses a HMT activity. Yet the recombinant, bacterially expressed $\mathrm{E}(\mathrm{z})$ protein was found to be inactive (Rea et al. 2000). We speculated that subunits in addition to $E(z)$, or covalent modifications, are necessary for HMT activity, and therefore, to investigate this possibility, we isolated the native human $\mathrm{E}(\mathrm{z}) \mathrm{com}$ plex.

We generated a cell line derived from 293 cells that stably expressed human ESC protein with an N-terminal Flag epitope tag (293-TAG). This tag allowed immunoaffinity purification of the Flag-ESC-E $(z)$ complex on anti-Flag antibody-containing resin. After loading the partially fractionated 293-cell nuclear extract onto the resin, proteins were eluted with excess Flag peptide. We decided to put the Flag tag on ESC rather than on E(z) because ESC is the best-known interaction partner of $\mathrm{E}(z)$; immunoprecipitation of Flag-ESC would purify the putative active E(z)-ESC complex from presumably inactive monomeric E(z), and Flag-ESC can be expressed at much higher levels than can the Flag-E(z) protein.

To ensure that Flag-ESC was efficiently expressed and incorporated into a multi-subunit complex, we fractionated nuclear extracts from 293-TAG cells on a sephacryl-
400 gel-filtration column. Figure 1A shows that FlagESC is found both as a monomer and as part of a complex of $\sim 500 \mathrm{kD}$. The elution profile of Flag-ESC in the complex partially overlapped with the elution profile of the endogenous $E(z)$ protein. The elution profile of $E(z)$ on sephacryl-400 (Fig. 1A) is broader than that of Flag-ESC and is shifted towards higher molecular weight fractions, suggesting that $\mathrm{E}(\mathrm{z})$ may be present in another multiprotein complex that does not contain ESC. Importantly, however, coelution of ESC with one of the E(z) peaks was observed.

The sephacryl-400 fractions that corresponded to either ESC in complex (the "complex" pool) or monomeric ESC ("monomeric" pool) were pooled and immunoprecipitated with anti-Flag antibodies. As a negative control, the same amount of nuclear extract from untagged 293 cells was fractionated on sephacryl-400 under identical conditions, and the fractions corresponding to the complex pool were pooled and immunoprecipitated in parallel. As seen in Figure 1B, endogenous E(z) protein was specifically coimmunoprecipitated with Flag-ESC from the 293-TAG complex pool. Thus, the stably expressed Flag-ESC protein was efficiently incorporated into a complex with endogenous $\mathrm{E}(\mathrm{z})$, and given its large size, this complex likely contains several previously unidentified subunits (see below).

Next, we sought to identify the components of the Flag-ESC-E $(z)$ complex. To this end, the complex and monomeric pools were precleared with protein A-agarose beads and subjected to immunoaffinity purification on anti-Flag antibody-containing resin. The bound proteins were eluted with excess Flag peptide and analyzed by SDS-PAGE and silver staining (Fig. 1C). As a negative control, the same procedure was carried out with the complex pool derived from untagged 293 cells. Five protein bands specific to the 293-TAG cells (p90, p85, p55, p50/p45) were observed (Fig. 1C). These polypeptides were excised from the gel, and the proteins were identified using two different types of mass spectrometry: mass fingerprinting using matrix-assisted laser desorption/ionization time-of-flight (MALDI-TOF) mass spectrometry (MS), and mass spectrometric sequencing using NanoES triple-quadrupole MS/MS. The p55 band was identified as the human ESC homolog (Eed), and the p90 band was identified as the human $E(z)$ homolog (EZH2), thus confirming the specificity of the immunopurification procedure. We did not find peptides corresponding to $E N X 1$, the second human homolog of $\mathrm{dE}(\mathrm{z})$.

The p50/p45 doublet was found to contain the histone binding proteins RbAp46 and RbAp48 (Fig. 1C). Their presence in the affinity-purified ESC-E(z) complex was confirmed by an independent immunoprecipitation experiment using anti-Flag antibody followed by Western blotting (Fig. 1B). The RbAp46/48 proteins interact directly with histone polypeptides and are commonly found to be subunits of protein complexes that have enzymatic activities involved in chromatin modification. Our identification of RbAp46 and RbAp48 as components of a human ESC-E $(z)$ complex is in agreement with a recent report showing that NURF55, the single Dro- 


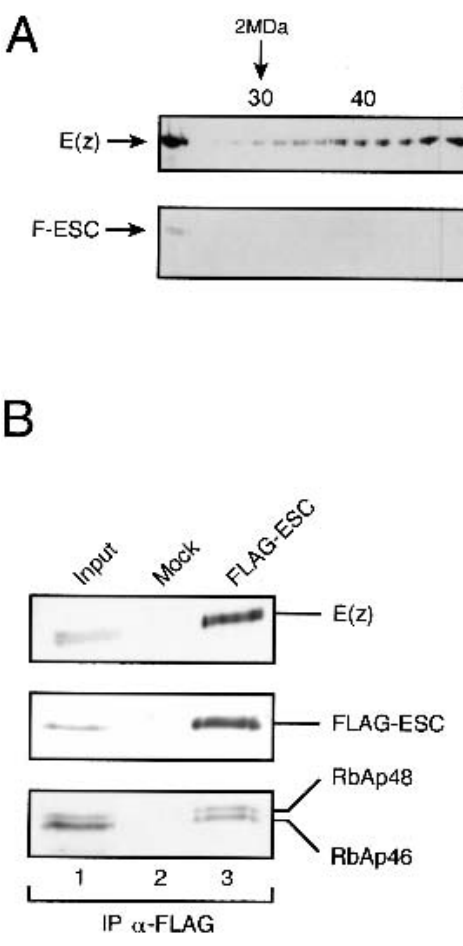

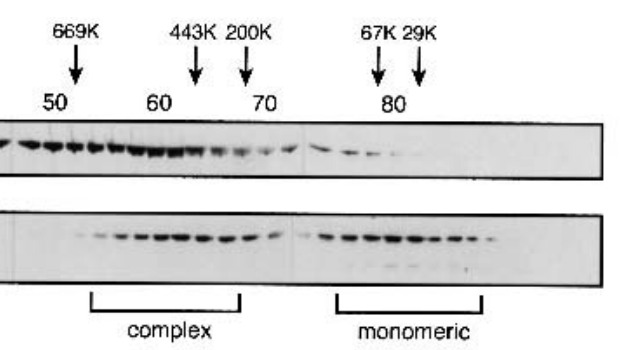

Figure 1. Isolation of the human Flag-ESCcontaining complex. $(A)$ Western blot analysis of the sephacryl-400 column fractions. Flag-ESC (F-ESC) was detected using antiFlag antibodies. $\mathrm{E}(z)$ was detected using antibodies raised against the recombinant protein (a gift of Dr. Otte). E(z) and Flag-ESC are indicated with arrows. Vertical arrows indicate the elution peaks of molecular size standards. The "complex" and "monomeric" pools used for anti-Flag immu-
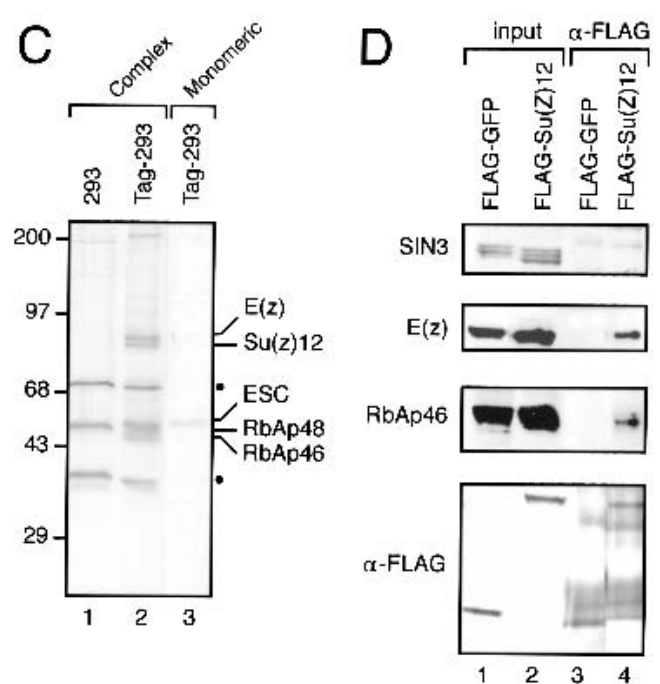
noffinity purification are indicated. $(B)$ Western blot analysis of the immunoaffinity-purified Flag-ESC complex. Input indicates $1 / 100(10 \mu \mathrm{L})$ of the complex pool from 293-TAG cell extracts used for antiFlag immunopurification; Flag-ESC indicates one tenth $(10 \mu \mathrm{L})$ of the peptide eluate from the anti-Flag affinity column; mock indicates one tenth of the peptide eluate from an anti-Flag affinity column that had been used to purify the complex pool from untagged cell extracts. IP, immunoprecipitation; $\alpha$-Flag, anti-Flag antibodies. (C) Silver staining of an SDS-polyacrylamide gel containing anti-Flag column peptide eluates. Complex and monomeric pools were derived from 293 and TAG-293 nuclear extracts through a sephacryl-400 column. The bands specific to the Flag-ESC complex are indicated. Dots indicate contaminating bands, which are also present in immunoprecipitates from the untagged cell extracts (293). The positions of molecular size standards are also indicated. $(D)$ Western blot of anti-Flag immunoprecipitates from 293 cells transiently transfected with Flag-GFP (negative control) or Flag-Su(z)12. Input indicates $1 / 100(\sim 10 \mu \mathrm{g})$ of the nuclear extract used for immunoprecipitation; $\alpha$-Flag lanes, one half of the peptide eluate fractions from the anti-Flag column.

sophila homolog of RbAp46 and RbAp48, is associated with the Drosophila ESC-E(z) complex (Tie et al. 2001). Although the Drosophila histone deacetylase (HDAC)Rpd3 can interact with the NURF55-ESC-E(z) complex in vitro, we were unable to detect HDAC1 or HDAC2 in our affinity-purified human ESC-E(z) complex by either mass-spectroscopic fingerprinting or Western blotting (data not shown, but see below).

The $\mathrm{p} 85$ band was identified as the JJAZ1 protein, one of the fusion partners of a chromosomal translocation common in a particular type of stromal tumor (Koontz et al. 2001). JJAZ1 also was identified as an E2F-inducible gene in an independent study (Weinmann et al. 2001). The JJAZ1 protein is a human homolog of the Drosophila protein $\mathrm{Su}(\mathrm{z}) 12$, which possesses the functional properties of both a $\mathrm{PcG}$ protein and a $\mathrm{Su}(\mathrm{var})$ protein (Birve et al. 2001). Su(z)12 is also a homolog of the Arabidopsis thaliana protein FIS2, which is important for fertilization-independent control of seed development (Luo et al. 1999). Notably, the A. thaliana homolog of $\mathrm{E}(z), \mathrm{FIS} 1$, was identified in the same genetic screen as FIS2, supporting the notion that the two proteins physically interact (Luo et al. 1999).

The Flag-ESC-associated proteins described above could represent the components of a single ESC-E $(z)$ complex. However, it is also possible that these proteins interact with ESC and/or with each other independently of $E(z)$. To distinguish between these possibilities, we transiently transfected 293 cells with an expression plasmid encoding Flag-tagged human $\mathrm{Su}(z) 12$ (JJAZ1) and subjected extracts derived from the transfected cells to immunoprecipitation with anti-Flag antibodies. As seen in Figure 1D, the endogenous $\mathrm{E}(\mathrm{z})$ and $\mathrm{RbAp}$ proteins were efficiently coimmunoprecipitated with Flag$\mathrm{Su}(z) 12$, suggesting that both $\mathrm{Su}(z) 12$ and $\mathrm{RbAp} 46 / 48$ exist in a complex with $\mathrm{E}(z)$.

Therefore, using a combination of gel filtration and anti-Flag immunoaffinity chromatography, we have isolated a human ESC-E $(z)$ complex and identified its three additional subunits as $\mathrm{Su}(z) 12$ (JJAZ1), RbAp46, and RbAp48. The complex contains histone methyltransferase activity with specificity towards histone H3 (see below). The lysine residues targeted by the complex are analyzed below. Because the proteins in the complex belong to the Polycomb group of proteins but are functionally different from the PRC1 complex, we referred to the complex isolated here as PRC2.

\section{Transient association of HDAC1 with the PRC2?}

In light of previous reports establishing an interaction between the histone deacetylases HDACl/2 with an 
ESC-E $(z)$ complex (van der Vlag and Otte 1999; Tie et al. 2001), and our failure to detect HDACs in the affinitypurified, biochemically defined PRC2, we attempted to characterize the human ESC-E(z) complex(es) through conventional chromatography. Proteins were extracted from the nuclear pellet fraction derived from HeLa cells and fractionated on different columns as described previously (Nishioka et al. 2002a,b) and summarized in Figure 2A. Briefly, proteins were separated on a DEAE-cellulose column. This analysis revealed three peaks of activity specific for histone $\mathrm{H} 3$ (Fig. 2A; data not shown). The peak of activity eluting earliest from the DEAE-cellulose column (peak III) contained ESC and E(z) (see below). Further fractionation of this protein peak on a gel filtration column demonstrated cofractionation of ESC and $\mathrm{E}(z)$, with H3-HMT activity eluting with an apparent mass of $\sim 500 \mathrm{kD}$ (Fig. 2C; data not shown). Importantly, further fractionation of the gel filtration pool on a DEAE$5 \mathrm{PW}$ column resulted in the resolution of two peaks of H3-HMT activity (Fig. 2B). In agreement with the affinity purification results described above (Fig. 1), Western blot analyses revealed that each peak of activity coeluted with $\mathrm{E}(\mathrm{z}), \mathrm{ESC}$, and the RbAp polypeptides (Fig. 2B) and, therefore, likely represented two distinct ESC-E(z) complexes. Importantly, complex I, but not complex II, coeluted with HDAC1, as detected by Western blot analysis (Fig. 2B). These results collectively establish that the ESC-E(z) complex can exist in at least two biochemically distinct complexes.

We attempted further purification of the DEAE-5PW complexes as described in Figure 2A. The last step of purification of complex II revealed coelution of HMT activity with the same polypeptides identified using the affinity purification procedure, described in Figure 1, as detected by Western blot analysis (Fig. 2C). Thus, this complex corresponds to PRC2. Purification of the pool I-ESC-E(z) complex was not successful. The complex was found to be labile and dissociated from HDAC1 (data not shown). Importantly, fractionation of complex I on the same column (DEAE-5PW) resulted in the recovery of activity eluting with the same profile as complex II (data not shown). These results strongly suggest that the ESC$\mathrm{E}(z)$ complex transiently interacts with HDAC1 and that PRC2 may represent a subcomplex of a larger ESC-E(z) complex.

\section{Characterization of the HMT activity of PRC2}

Next, we analyzed the substrate specificity of the purified PRC2. As seen in Figure 3A, the conventionally purified PRC2, like the affinity-purified complex contained histone $\mathrm{H} 3$ methyltransferase activity. PRC2 (native, Fig. 3A; or affinity purified, data not shown) was active when octamers were used as substrate. Because chromatin, rather than a histone octamer, is likely to be the natural substrate of PRC2, we tested whether the complex could methylate oligonucleosomes. As seen in Figure $3 \mathrm{~A}$, the ESC-E(z) complex was indeed able to methylate oligonucleosomes. Interestingly, the HMT activity of PRC2 was weaker with oligonucleosomes reconsti- tuted with recombinant bacterially produced histones (Fig. 3A, cf. lanes 7-9 and 10-12). This effect appears specific to oligonucleosomes and was not caused by differences in the amounts of substrate (Fig. 3A, bottom), and it suggests that other modifications present in the human isolated histone polypeptides, but absent in the bacterially produced histones, stimulate the activity of PRC2 in a nucleosome-specific manner. Alternatively, the difference in amino acid sequence between the human and Xenopus (used to reconstitute recombinant nucleosomes) $\mathrm{H} 2 \mathrm{~A} / \mathrm{H} 2 \mathrm{~B}$ polypeptides, might account for the observed differences.

Our next goal was to identify the histone $\mathrm{H} 3$ residues methylated by PRC2. The histone $\mathrm{H} 3$ tail contains three lysines that can serve as potential substrates for the ESC$\mathrm{E}(z)$ HMT: Lys 4 (K4), K9, and K27. To analyze this issue, we performed three independent assays.

Purified PRC2 was incubated with octamers in the presence of ${ }^{3} \mathrm{H}$-SAM, and the radiolabeled-H3 polypeptides were recovered from an SDS-polyacrylamide gel and subjected to Edman degradation. As seen in Figure $3 \mathrm{~B}$, two apparent peaks of radioactivity were observed: one peak coincided with K9, and the second peak mapped to residues around K27; no radioactivity associated with $\mathrm{K} 4$ was recovered. Because the efficiency of radioactivity recovered decreases as the number of microsequencing cycles increases, and because the peak at K27 had similar intensity as the peak at K9, K27 may be a preferred site. However, the fact that K9 was also detected strongly suggests that both $\mathrm{K} 9$ and $\mathrm{K} 27$ are recognized by the ESC-E $(z)$ complex in vitro, under the conditions used. We further analyzed the lysine specificity by reconstituting octamers in which $\mathrm{K} 9$ and/or K27 were mutated to alanine. The result of this analysis agrees with the results obtained using Edman degradation and demonstrates that both $\mathrm{K} 9$ and $\mathrm{K} 27$ are sites recognized by the complex, but that $\mathrm{K} 27$ is a preferred site, in vitro, under the conditions used (Fig. 3C). We further investigated the issue of lysine-substrates for the ESC-E(z) HMT by using a set of GST-H3 tail fusion proteins. All possible pair-wise combinations of the three possible lysines of the H3-tail were mutated to arginines [K9R/K27R (K4), K4R/K9R (K27), and K4R/K27R (K9); Tachibana et al. 2001]. PRC2 specifically methylated the wild-type H3 tail and the $\mathrm{H} 3$ tails that had only K9 or K27 available for methylation; the complex failed to methylate the $\mathrm{H} 3$ tail in which both K9 and K27 were mutated to arginines (Fig. 3D). Surprisingly, under the conditions of the assay, both K9 and K27 were equally recognized as substrates. We concluded that the human ESC-E(z) complex targets histone $\mathrm{H} 3$ and can recognize $\mathrm{K} 9$ and K27. The preference for these two sites is likely to be a regulated process (see Discussion).

\section{The SET domain of $E(z)$ is required for histone methyltransferase activity of PRC2}

The SET domain of $E(z)$ is highly homologous to that of Su(var)3-9, G9A, PR-Set7, and Set9 (Fig. 4A). In particular, the E(z) SET domain contains the conserved histidine 

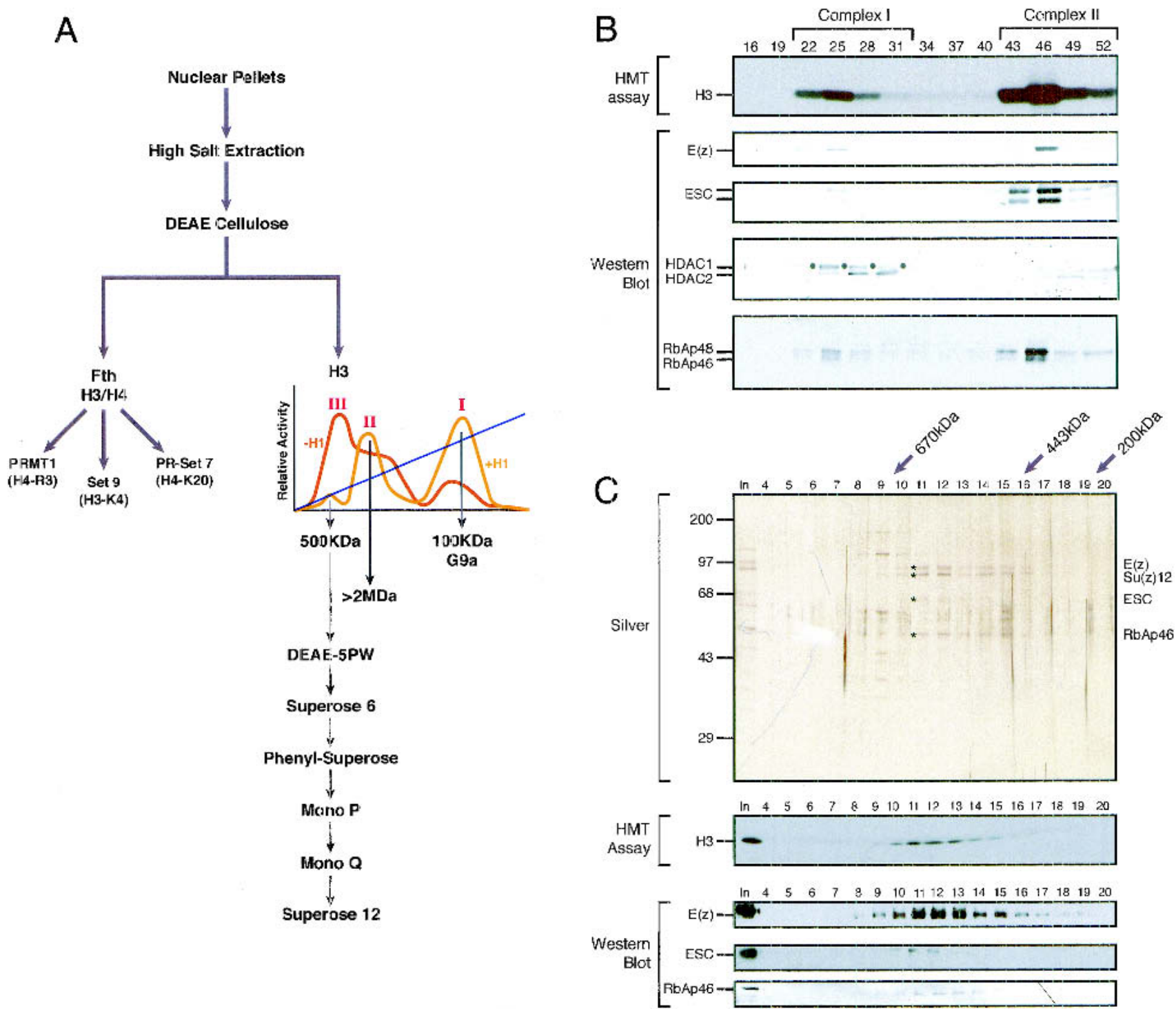

Figure 2. Conventional purification of the E(z)-ESC complex. (A) Schematic representation of the purification procedure utilized to isolate the PRC2 as well as other HMTs. The three H3-specific HMTs bound to the DEAE-cellulose column are indicated as I, II, and III. The brown curve shows HMT activity of DEAE-cellulose fractions on oligonucleosomes in the absence of histone H1, and the orange curve shows the activity in the presence of H1. Performing HMT assays with and without histone H1 allowed us to clearly differentiate the three different peaks of activity bound to the column. Each of the peaks were further fractionated on a gel filtration column as described by Nishioka et al. $(2002 \mathrm{a}, \mathrm{b})$. The native molecular weight of the different H3-HMTs are indicated. The steps of purification of the 500-kD activity, PRC2, are shown and described in the Materials and Methods section. $(B)$ HMT assay and Western blot analysis of the DEAE-5PW column. The pool derived from the gel filtration step was fractionated onto a DEAE-5PW column. Fractions of the column were assayed for HMT activity using histone octamers as substrates. The presence of different polypeptides was determined by Western blot. Two peaks of HMT activity were observed coeluting with E(z) and other PRC2 components. These peaks are referred to as "complex I" and "complex II". The protein identified as HDAC, which copurifies with complex I, is marked by dots. (C) Analysis of the final step of PRC2 purification chromatography on a gel filtration Superose 12 column. The top panel shows silver staining of fractions $(10 \mu \mathrm{L})$ derived from the Superose 12 column. The bands coeluting with HMT activity are indicated by asterisks; elution peaks of molecular size standards, on the top. The positions of SDS-PAGE molecular weight markers are indicated on the left. The middle panel shows the HMT assay with Superose 12 fractions $(10 \mu \mathrm{L})$ using recombinant histone octamers as substrates. The position of histone $\mathrm{H} 3$ is indicated. The bottom panels show Western blot analysis of Superose 12 fractions using the indicated antibodies.

residue (H689) in the NHS consensus sequence shown to be essential for the HMT activity of all the proteins mentioned above (Rea et al. 2000; Tachibana et al. 2001; Wang et al. 2001a; Nishioka et al. 2002a,b). Therefore, we tested whether substitution of $\mathrm{H} 689$ with an alanine (H689A) would affect the HMT activity of the human $\mathrm{E}(z)$ protein complex. We transiently expressed Flagtagged wild-type $\mathrm{E}(z)$ and H689A-containing $\mathrm{E}(z)$ protein 
A
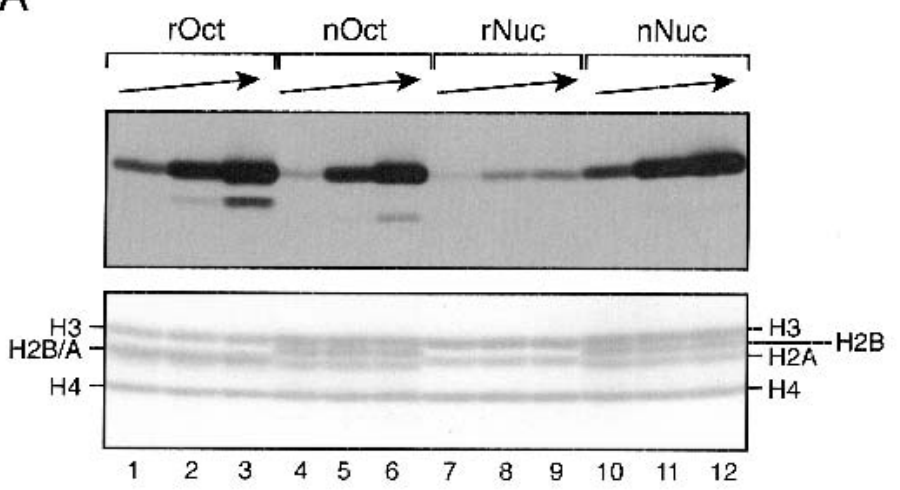

B

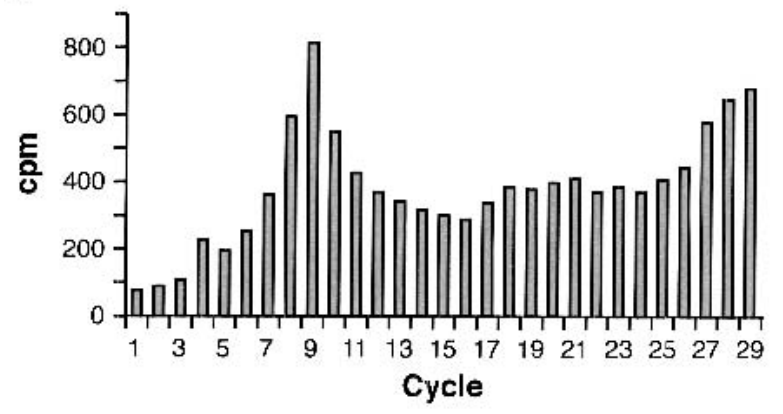

C
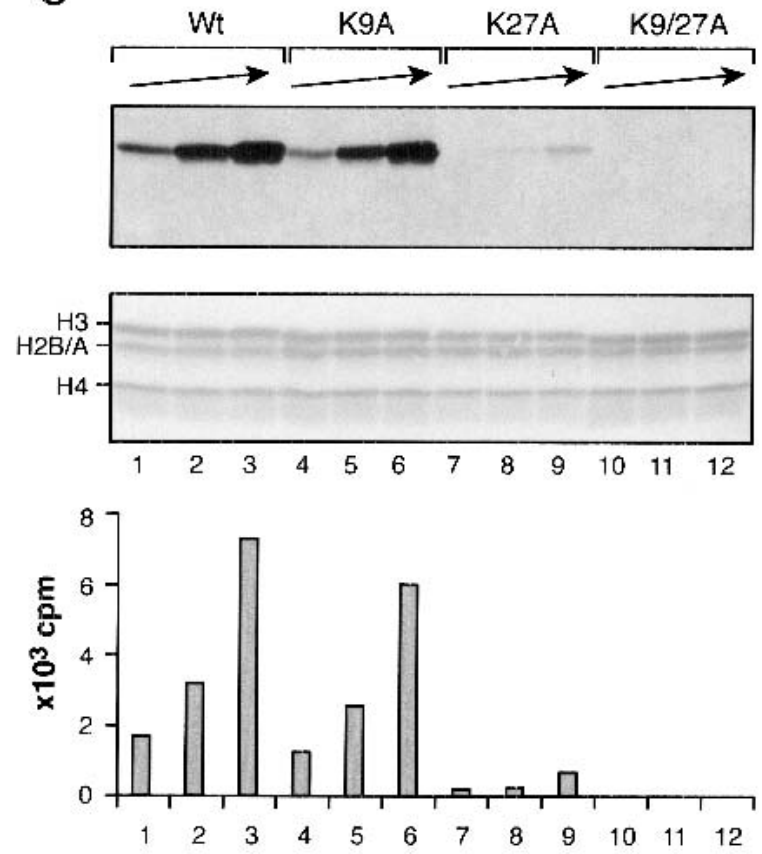

D

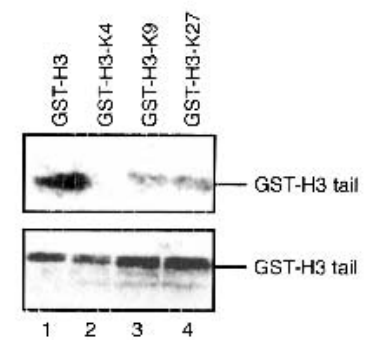

Figure 3. Characterization of the HMT activity of PRC2. (A) Substrate specificity assay with conventionally purified E(z)-ESC complex. The different substrates used are recombinant octamer (rOct), native HeLa octamer (nOct), oligonucleosome assembled in vitro using recombinant histones (rNuc), and oligonucleosome assembled in vitro using native histones (nNuc). Arrows indicate the addition of different amounts of PRC2. The top panel shows an autoradiograph and the bottom panel shows Coomassie blue staining of the HMT assay membrane. Positions of different histones are indicated. Migration of recombinant histones is indicated on the left side and migration of the native purified HeLa histones is indicated on the right side. $(B)$ Edman degradation performed on isolated histone H3 using native core histones as a substrate. Products of the HMT reaction were separated with SDS-PAGE, and the labeled H3 polypeptide was excised and subjected to Edman degradation. The numbers at the bottom represent the cycles of degradation and correspond to the amino acid of the $\mathrm{H} 3$ tail. $(C)$ Determination of methylation site preference of the PRC2. HMT assays were performed with octamers assembled with recombinant histones using either wild-type (Wt) histone $\mathrm{H} 3$, or histone $\mathrm{H} 3$ containing the following amino acid substitutions: $\mathrm{K} 9$ to alanine (K9A), K27 to alanine (K27A), and a substitution of K9 and K27 to alanine (K9/27A) as indicated. Arrows indicate the addition of different amounts of purified PRC2. The top panel is an autoradiograph, the middle panel is a Coomassie blue staining of the HMT assay membrane, and the bottom panel is quantification of the autoradiograph. $(D)$ Determination of preferred methylation sites on histone H3 using GST-fusion proteins in which the candidates methylation sites were substituted as indicated. Anti-Flag affinity-purified E(z)-ESC complex was used in the analysis. GST-H3 indicates the wild-type H3 tail; GST-H3-K4, an H3 tail in which K9 and K27 have been mutated to arginines (K9R/K27R); GST-H3-K9, the K4R/K37R mutant; and GST-H3-K27, the K4R/K9R mutant. Top and bottom panels are the same as in $A$.

in 293 cells. As seen in Figure 4B, anti-Flag immunoprecipitates from 293 cells transfected with wild-type E(z) protein showed strong H3-HMT activity, as expected. In contrast, immunoprecipitates from 293 cells transfected with the H689A mutant had significantly reduced HMT activity, suggesting that an intact SET domain in $\mathrm{E}(z)$ is necessary for the HMT activity of PRC2.

We further extended these studies on the requirement of the SET-domain for HMT activity by analyzing two well-characterized alleles of the Drosophila $\mathrm{E}(z)$ protein. One allele carries a single substitution of the conserved cystein-545 to tyrosine within the Pre-SET domain (C545Y). Flies carrying this substitution are temperature-sensitive and importantly, at the restrictive temperature, show loss of binding of $E(z)$ and other PcG group proteins to Polycomb Repressive Element (PRE; Carrington and Jones 1996). The other allele, E(z) Trm contains a replacement at arginine 741 and behaves pheno- 


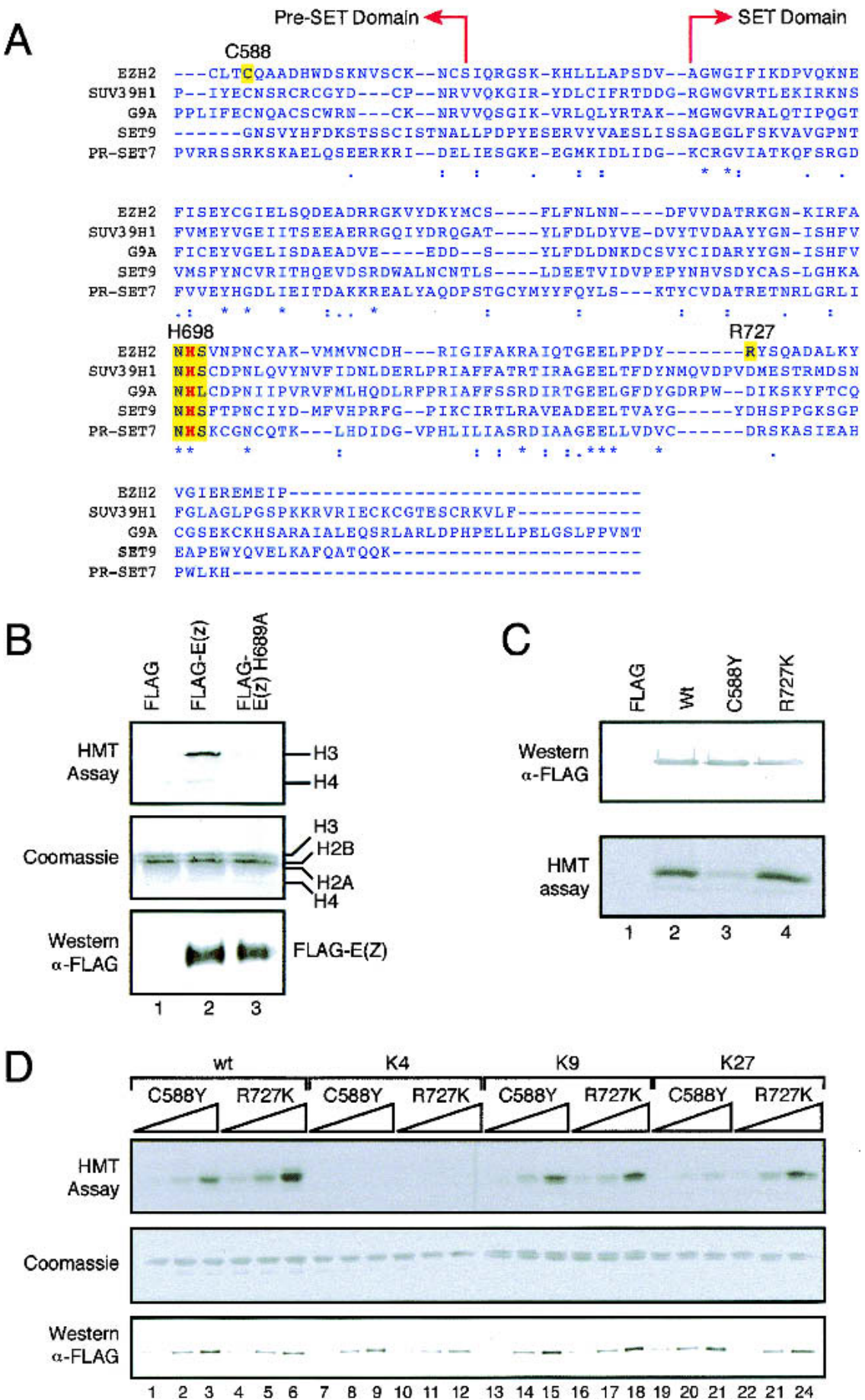

Figure 4. HMT activity of PRC2 containing mutant $\mathrm{E}(z)$ protein. (A) Alignment of the SET domains of Ezh2 [the mouse homolog of E(z)], SUV39H1, G9A, Set9, and PR-Set7. Alignment was performed using the CLUSTALW algorithm at the European Bioinformatics Institute server (http:// www2.ebi.ac.uk/clustalw; Thompson et al. 1994). The NHS consensus within the SET domain is indicated by yellow. The conserved histidine 689 is shown in red and the C588 and R727 residues are indicated in yellow. The borders of the SET and PreSET domains are shown. (B) HMT assays with PRC2 purified from transfected cells containing the wild-type $\mathrm{E}(z)$ protein or the catalytic site mutant. The PRC2 were purified by anti-Flag immunoaffinity chromatography from 293 cells transfected with either an empty expression vector control (Flag), or expression vectors encoding wildtype $E(z)$ [Flag-E(z)] or the H689A mutant [Flag-E(z) H689A]. Nuclear extracts ( 1 mg) were immunoprecipitated with anti-Flag M2 agarose, and the peptide eluates $(10 \mu \mathrm{L}$ out of $20 \mu \mathrm{L}$ ) were used for the HMT assays. The top panel shows an autoradiograph, the middle panel shows a Coomassie blue staining of the HMT assay membrane, and the bottom panel shows an anti-Flag Western blot of the HMT assay reaction. $(C)$ HMT assays were performed as in $B$ using affinity-purified PRC2 containing wildtype $(\mathrm{Wt}) \mathrm{E}(\mathrm{z})$ protein or the C588Y and $\mathrm{R} 727 \mathrm{~K}$ mutants. The top panel is anti-Flag Western blot and the bottom panel is an autoradiograph of the HMT assay. (D) Methylation site preference of affinity purified PRC2 complexes containing the C588Y or R727K E(z) mutant. The GST-H3 tail fusion proteins-wild-type (wt), double K9/K27 mutant (K4), double K4/K27 mutant (K9), and double K4/K9 mutant (K27) were methylated using increasing amounts of indicated mutant PRC2 complexes. The top panel shows the autoradiograph of the HMT assay, the middle panel shows the Coomassie stain showing equal amounts of GST substrates used in the analysis, and the bottom panel shows anti-FLAG Western blot demonstrating that each set of assay received approximately equal amounts of complex. typically as a strong dominant trithorax mutation and does not affect the binding of PcG proteins to PREs (Bajusz et al. 2001).

We generated expression vectors carrying human $\mathrm{E}(\mathrm{z})$ proteins with the mutations described above. Flag-tagged wild-type E(z) and mutant forms C588Y (corresponding to Drosophila C545Y mutant) and R727K (corresponding to Drosophila R741K mutant) were transiently expressed in 293 cells. The PRC2 carrying the E(z) mutations were isolated as described above and analyzed for HMT activ- ity. This analysis showed that the $E(z)$ mutant protein that affects binding of PcG proteins to PRE was drastically reduced in its ability to methylate histone $\mathrm{H} 3$. Importantly, the mutant that does not affect binding of PcG proteins to PRE, E $(z)^{T r m}$, retained HMT activity which appears indistinguishable from the wild-type protein (Fig. 4C). The differences observed in HMT activity were not caused by different expression levels of the mutant proteins, as equal amount of complexes were analyzed (Fig. 4C; data not shown). Thus, we concluded that the 
C588Y mutation inhibits the HMT activity of PRC2 either by directly affecting the catalytic activity of $E(z)$ HMT or by disrupting the interaction of $\mathrm{E}(z)$ protein with one of the PRC2 subunits.

Next, we wanted to test whether the C588Y mutation can differentially affect methylation of K9 and K27 on the histone H3 polypeptide. We also wanted to test whether the Trithorax-mimic mutation of $E(z)(R 727 K)$ could cause a change in methylation site preference without affecting the overall levels of histone H3 methylation. To this end, PRC2 complexes containing mutant $\mathrm{E}(\mathrm{z})$ proteins were analyzed using GST-H3 tail fusion proteins in which only $\mathrm{K} 9$ or $\mathrm{K} 27$ is available for methylation (Tachibana et al, 2001). As seen in Figure 4D, the R727K mutant was able to methylate equally well both $\mathrm{K} 9$ and $\mathrm{K} 27$, thus being undistinguishable from the wild-type protein (see Fig. 3D; data not shown). Interestingly, the C588Y mutant showed a specific reduction of methylation of $\mathrm{K} 27$ without a reduction of methylation of K9. Therefore, loss of K27 methylation correlates with the Polycomb phenotype and mislocalization of PcG proteins observed in the corresponding Drosophila mutant.

\section{Methylation of the H3-tail at K27 provides a mark for PC1 binding}

The studies shown in the previous section led us to hypothesize that methylation of histone $\mathrm{H} 3$ by $\mathrm{E}(\mathrm{z})$ within PRC2 provides a "mark" to which the PRC1 binds. To directly test this hypothesis, different H3-tail peptides individually trimethylated at each of the three lysine candidates for methylation were synthesized and used to analyze binding of PC1, a component of the PRC1 (Fig.
5A). In addition, a peptide containing dually trimethylated $\mathrm{K} 9$ and $\mathrm{K} 27$ was also tested. In these studies, PC1 was obtained by in vitro translation. The HP1 protein that specifically binds to methylated $\mathrm{K} 9$ was used as a control.

As expected, HP1 specifically bound to the H3 tail peptide methylated at $\mathrm{K} 9$ (Fig. 5B). In contrast, the PC1 protein bound specifically to the $\mathrm{H} 3$ peptide methylated at K27, but did not bind either to unmodified peptide or to $\mathrm{H} 3$ peptides methylated at $\mathrm{K} 9$ or K4 (Fig. 5B). Interestingly, simultaneous methylation of K9 and K27 precluded binding of $\mathrm{PC} 1$ to the $\mathrm{H} 3$ tail peptide, under the conditions of the assay. This effect was specific for PC1, because HP1 retained its ability to bind to the doubly methylated peptide.

We also noted that the specificity of recognition of the methyl-peptides could be affected by the binding assay conditions. As illustrated at the bottom of the panel, increase in salt concentration and addition of nonspecific competitor (BSA) selectively eliminated recognition of the doubly K9/27-methylated peptide by HP1 without affecting the recognition of the K9-methylated peptide (Fig. 5B). These more stringent conditions also reduced binding of PC1 to the methyl-K27 peptide (data not shown). These results suggest that recognition of a mark (set by PRC2) can be influenced by different factors such as local chromatin structure or presence of competing proteins.

\section{Discussion}

Multiple functions of the E(z) complex

We have isolated a human ESC-E(z) complex, PRC2, and demonstrated that it possesses HMT activity with speci-
Figure 5. Interaction of $\mathrm{PCl}$ protein with $\mathrm{H} 3$ tail methylated at $\mathrm{K} 9$ and $\mathrm{K} 27 .(A)$ Schematic representation of the different peptides used in the pull-down assays shown in panel $B$. In vitro translated mPC1 $\left({ }^{35} \mathrm{~S}-\mathrm{mPC} 1\right)$ or HP1 $\left({ }^{35} \mathrm{~S}-\mathrm{HP} 1\right)$ proteins were incubated with immobilized H3 tail peptides containing the following modifications: trimethyl-K4 (mK4), trimethyl-K9 (mK9), trimethyl-K27 (mK27), and trimethyl-K9 together with trimethylK27 (mK9/27) or with unmodified H3 tail peptide (unmodified). (B) The binding assays were washed as described in Materials and Methods, and the proteins remaining bound to the peptides were analyzed by SDS-PAGE followed by autoradiography. The top panel shows PC1-binding to indicated peptides without competitor BSA and the middle and bottom panels show HP1 binding to indicated peptides in absence (middle) or presence (bottom) of competitor BSA. The sequence of the peptides and the scheme of the experiment are illustrated on the top of panel $A$.
A

H3 tail: ARTKQTARKSTGGKAPRKQLATKAARKSAPAT...
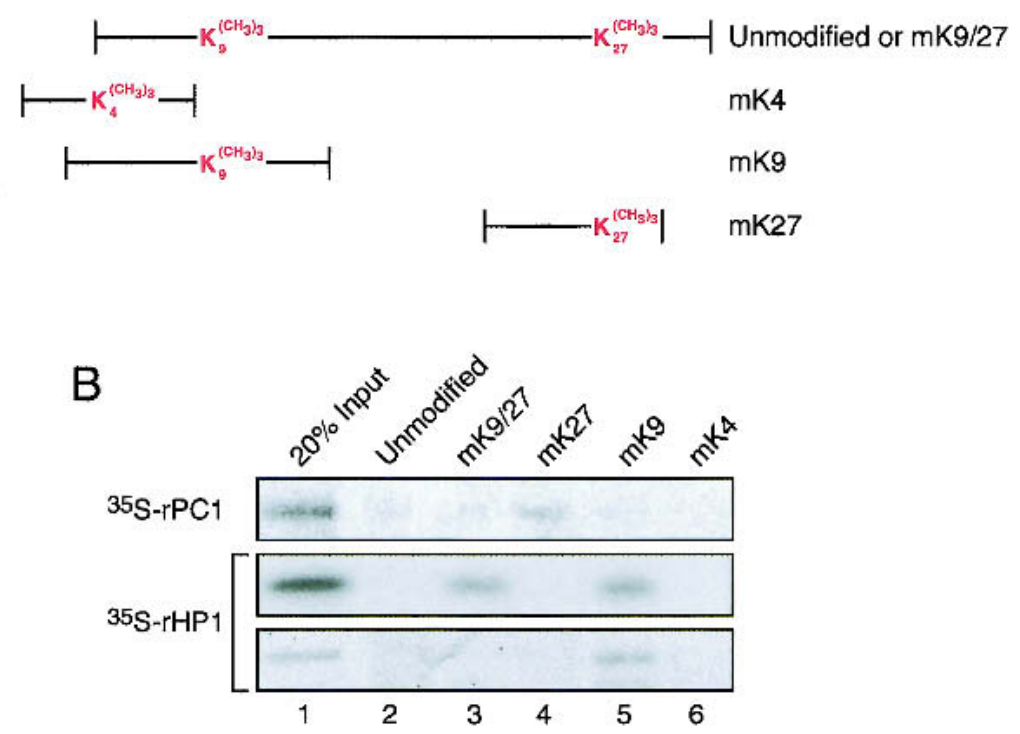
ficity for the histone $\mathrm{H} 3$ tail. Our results provide new insight into the mechanism of action of the $\mathrm{E}(z)$ protein. The polypeptide composition of the PRC2, specifically the presence of $\mathrm{Su}(\mathrm{z}) 12$, suggests that PRC2 plays a more general role in transcriptional silencing outside of the repression of $\operatorname{HOX}$ genes. Su(z)12 is a protein with dual PcG and Su(var) functions (Birve et al. 2001), and this, therefore, suggests that PRC2 has functions other than homeotic gene repression and, in fact, may play a more general role in heterochromatin-mediated silencing. The observation that human $\mathrm{E}(\mathrm{z})$ can function as an inducer of silencing in yeast and as an enhancer of PEV in Drosophila supports this notion (Laible et al. 1997). We speculate that the requirement for $\mathrm{E}(z)$ and ESC during early embryonic development reflects its function in general transcriptional silencing. The multifunctional nature of both the $\mathrm{E}(\mathrm{z})$ and $\mathrm{Su}(z) 12$ proteins suggests that they may also display biochemical heterogeneity. For example, the heterogeneous elution profile of $E(z)$ on the sephacryl-400 (Fig. 1A) and MonoP (data not shown) columns suggests that $\mathrm{E}(z)$ exists in several distinct complexes.

\section{Is the H3-K27 or K27 and K9 recognized as substrates} by $E(z)$ ?

Purified PRC2 displayed specificity for K9 and K27 of the histone $\mathrm{H} 3$ tail. The complex, under the conditions of our assays, displayed a strong preference for K27. When the H3-tail was used as a GST-fusion protein; however, PRC2 displayed apparently equal specificity for K9 and K27. Analyses of the amino acid sequence in which these lysines are embedded shows a great deal of conservation. $\mathrm{K} 9$ is present within the sequence QTARK, STG, whereas K27 is present within the sequence $\mathrm{KAARK}_{27} \mathrm{SAP}$. Therefore, at least two different possibilities can be postulated to account for the specificity observed. In one case, the specificity of PRC2 is relaxed in vitro, under the assay conditions used, and the methylation of $\mathrm{K} 9$ is nonspecific because of the sequence similarity of the residues within which K9 resides. An apparently similar situation was observed in studies analyzing the specificity of the HMT G9a, which biochemically behaves as a H3-HMT that preferentially targets K9 and, to much lower levels, K27 (Tachibana et al. 2001). In vivo, however, G9a clearly targets H3-K9; whether or not the extent of H3-K27 methylation is decreased in G9anull cells is unknown (Tachibana et al. 2002). A second possibility is that $\mathrm{E}(\mathrm{z})$ targets both $\mathrm{K} 9$ and $\mathrm{K} 27$, but that this is a regulated process such that methylation of K9 and/or K27 is modulated by factors that associate with $\mathrm{E}(z)$ and/or by other modifications existing in the nucleosome. We favor this second possibility based on the following observations. First, the $\mathrm{E}(\mathrm{z})$ protein can be considered to be a PcG as well as a TrxG (Bajusz et al. 2001). Not surprisingly, our analyses demonstrated that $E(z)$ is present in distinct complexes (Fig. 1A). One of the complexes containing $\mathrm{E}(z)$ is PRC2; however; this complex also included $\mathrm{Su}(z) 12 . \mathrm{Su}(z) 12$ is a polypeptide that has been found in genetic analyses to regulate the expression of the HOX genes, but loss of function of Su(z)12 suppresses PEV (Birve et al. 2001). Therefore, the presence of $\mathrm{Su}(z) 12$ in PRC2 may regulate the methylation sites within the histone $\mathrm{H} 3$ tail.

Methylation of histone H3-K9 was shown to be an essential step in the establishment of inactive $\mathrm{X}$ chromosome (Heard et al. 2001; Boggs et al. 2002; Peters et al. 2002). H3-Lys 9 methylation of the inactive $X$ chromosome is not mediated by Suv39 (Peters et al. 2002) or by G9a (Tachibana et al. 2002). Studies have demonstrated that the imprinted inactivation of the $\mathrm{X}$ chromosome in females is lost in mutant mice lacking eed (the mammalian homolog of ESC; Wang et al. 2001b). Moreover, studies have also demonstrated that during imprinted $\mathrm{X}$ inactivation, the mammalian ESC-E $(z)$ complex is localized to the inactive $\mathrm{X}$ chromosome in a mitotically stable manner (Mak et al. 2002). We speculate, in light of the accumulated data, that H3-K9 methylation of the inactive $\mathrm{X}$ chromosome might be mediated by $\mathrm{E}(z)$ within PRC2 or a PRC2-like complex. Importantly, however, the function of methylation of histone H3 at K27 has not been analyzed in the establishment and/or maintenance of the inactive $\mathrm{X}$ chromosome. In light of the results discussed above, we postulate that methylation of H3-K27 may also be important in the process of $\mathrm{X}$ inactivation.

\section{How does PRC2 function in repression of HOX genes?}

We propose that the role of E(z) HMT activity in the repression of homeotic gene expression is to establish a binding site for other PcG proteins. We suggest that PRC2 is recruited to the HOX gene cluster by a transiently acting repressor, for example, through an EEDYY1/Pho interaction (Satijn et al. 2001) or an RbAp46/ 48-HDAC/dMi2/Hb interaction (Kehle et al. 1998; see below). Once recruited, PRC2 methylates K27 on histone $\mathrm{H} 3$, and this mark recruits $\mathrm{PC} 1$. The $\mathrm{PC} 1$ protein can convert this mark into a permanently repressed state through methylation of $\mathrm{K} 9$ through the recruitment of the Su(var)3-9 H3-K9-specific histone methyltransferase (Sewalt et al. 2002) and/or the recruitment of PRC1 (Shao et al. 1999). Alternatively and/or additionally, PC1 may stimulate the H3-K9 HMT activity of PRC2. This hypothesis is supported by our studies demonstrating that trimethylation of $\mathrm{K} 27$ is necessary for binding of $\mathrm{PC} 1$ to an $\mathrm{H} 3$ tail peptide. Our findings are in full agreement with studies demonstrating loss of chromosome binding for several PRC1 components upon inactivation of $E(z)$ (Rastelli et al. 1993). Interestingly, immunolocalization experiments using antibodies specific for methylated H3-K9 suggest that almost all of the H3-K9 methylation is concentrated in the chromocenter of Drosophila polytene chromosomes, with almost no staining detectable on the chromosomal arms (Nishioka et al. 2002b). In contrast, $\mathrm{E}(z)$ and other PcG proteins, with subnuclear localization that is regulated by $\mathrm{E}(z)$, bind only to discrete bands along the arms of polytene chromosomes (Rastelli et al. 1993). These observations suggest that methylation at $\mathrm{K} 27$, rather than methylation at $\mathrm{K} 9$, is 
more likely to establish a binding site for the PC1 protein. This may explain why methylation of K9 alone was not sufficient to allow PC1 to recognize specifically the H3 tail in vitro (Lachner et al. 2001). The observed PC1 binding was independent of DNA. However, repression of $H O X$ genes in vivo is dependent on PRE. From these results, we must conclude that although methylation of the $\mathrm{H} 3$ tail is important in creating a recognition site for PC1 binding, stable and specific binding must require additional factors and or modifications. A likely candidate is a nucleosome on the PRE with the histone H3-tail methylated at position 27 .

\section{PRC2 and histone deacetylases}

The presence of the RbAp46 and RbAp48 proteins in the ESC-E $(z)$ complex may be important for several reasons. First, these histone-binding proteins are often found in complexes with enzymes involved in the covalent modification of histones. For example, RbAp46 is essential for substrate recognition by, and enzymatic activity of, the histone acetyltransferase enzyme Hatl (Verreault et al. 1998). Therefore, we speculate that the inability to detect HMT activity in preparations of recombinant $\mathrm{E}(\mathrm{z})$ protein (Rea et al. 2000) is owing, in part, to the lack of the $\mathrm{RbAp} 46 / \mathrm{RbAp} 48$. Another implication of the presence of $\mathrm{RbAp}$ proteins in the $\mathrm{E}(z)$ complex is that they might facilitate interaction with HDACs. During development, GAP proteins facilitate repression of the HOX genes. GAP proteins, such as Hunchback, are short-lived (Beuchle et al. 2001). Hunchback represses HOX genes by recruiting the Drosophila homolog of human Mi-2 protein (Kehle et al. 1998), a constituent of the NuRD complex which also contains HDACs 1 and 2 and RbAp46/RpAp48 (Zhang et al. 1998). An interesting possibility is that HDACs or RbAp proteins initially recruited by Hunchback can later recruit PRC2 containing HMT activity via interaction with $\mathrm{E}(z)$. This may constitute a switch from short-term to long-term repression.

In support of this hypothesis, PRC2 contains $\mathrm{E}(\mathrm{z})$ and
RbAp proteins. In addition, there is strong experimental evidence for an interaction between HDACs and $E(z)$ (van der Vlag and Otte 1999; Tie et al. 2001). One function of the E(z)-HDAC interaction is to deacetylate histones so that the $\mathrm{E}(\mathrm{z})$-containing complex can methylate them. A similar mechanism was found to operate in yeast, in which methylation of $\mathrm{H} 3-\mathrm{K} 9$ by $\mathrm{Clr} 4$ requires deacetylation of H3-K9 and Lys 14 (K14) by Clr6 and Clr3, respectively (Nakayama et al. 2001). A similar mechanism is likely to operate in higher eukaryotes as acetylation and methylation are mutually exclusive marks, and methylation of $\mathrm{H} 3-\mathrm{K} 9$ by Suv39h1 requires deacetylation of this residue (Rea et al. 2000). Our findings demonstrating two distinct ESC-E $(z)$ complexes (Fig. 2B), one of which coelutes with HDAC1, raises the possibility that the PRC2 can transiently associate with an HDAC complex. This observation raises the possibility that PRC2 HDAC1 may be a highly-specialized complex dedicated to the methylation of H3-K27, which apparently is not acetylated in vivo in higher eukaryotes. Therefore, it is possible that these two different ESC-E(z) multiprotein complexes establish different marks on the histone $\mathrm{H} 3$ tail (Fig. 6).

\section{Materials and methods}

Immunoaffinity purification

of a Flag-ESC-containing complex

A human ESC cDNA was subcloned into the pCMV-Flag-4 mammalian expression vector (Kodak) in frame with the Flag epitope. The Flag-ESC construct was transfected into 293 cells using the Effectene reagent (Qiagen), and stable transformants were selected for 2 weeks on Dulbecco's modified Eagle medium (DMEM) supplemented with 10\% bovine calf serum and 1 $\mathrm{mg} / \mathrm{mL}$ G418. G418-resistant clones were analyzed for expression of Flag-ESC, and the highest expressing clone was expanded.

For immunoaffinity purification of Flag-ESC, $\sim 3 \times 10^{9} 293$ Flag-ESC cells were harvested, and nuclear extracts were prepared as described (Dignam et al. 1983). The nuclear extract ( 30
Figure 6. Model depicting the establishment of two different "marks" on the histone H3-tail. (Middle) The H3-tail and the lysines (red) that are functionally known to be acetylated in vivo, as well as K4 and K27 (blue) that are methylated but apparently not acetylated in higher eukaryotes. (Top) The marks established by PRC2 when it functions together with histone deacetylase. In this case, K9 (and possible K14, Lys 18, and Lys 23 ) is deacetylated, creating a site (K9) that can be accessed by PRC2. In this manner PRC2 methylates both $\mathrm{K} 9$ and K27. (Bottom) PRC2 in the absence of a histone deacetylase can methylate only K27, creating a "mark" on the histone $\mathrm{H} 3$ tail that is functionally different from that shown in the top panel. In this case, K9 remains acetylated.

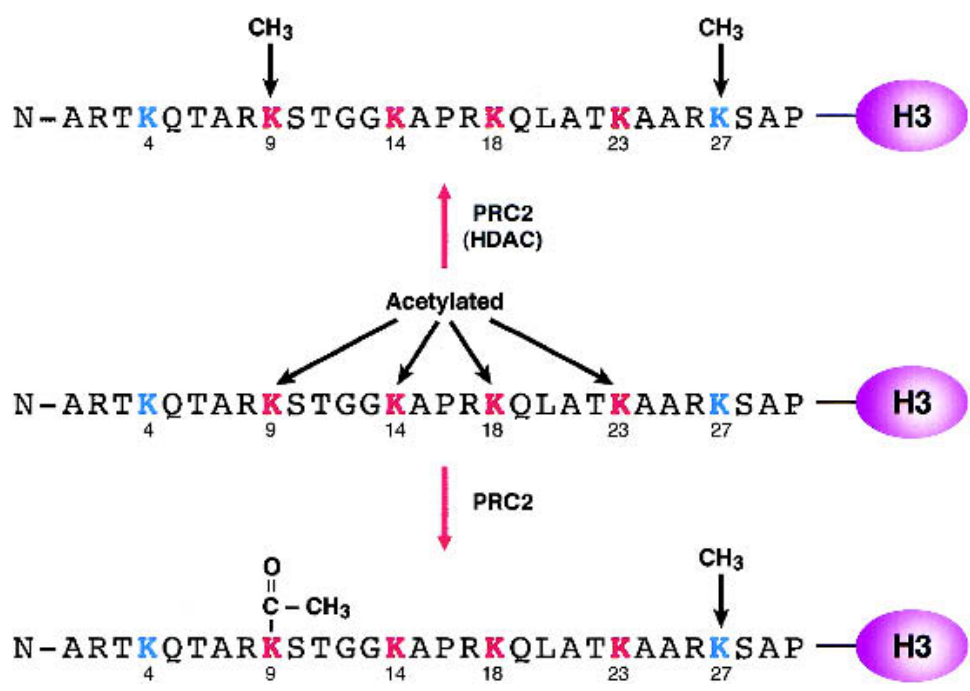


mg total protein) was precipitated with $75 \%$ saturated ammonium sulfate, and the precipitated proteins were redissolved in $2 \mathrm{~mL}$ of buffer $\mathrm{BC}(10 \%$ glycerol, $50 \mathrm{mM}$ Tris- $\mathrm{HCl}$ at $\mathrm{pH} 7.9$ and $4^{\circ} \mathrm{C}, 0.2 \mathrm{mM}$ EDTA, $10 \mathrm{mM}$ 2-mercaptoethanol, $0.2 \mathrm{mM}$ phenylmethylsulfonyl fluoride) containing $500 \mathrm{mM} \mathrm{KCl}$. The concentrated nuclear extract was fractionated on a $120-\mathrm{mL}$ sephacryl-400 (Pharmacia) column in the same buffer. Fractions of $1 \mathrm{~mL}$ were collected at a flow rate of $1 \mathrm{~mL} / \mathrm{min}$. Fractions that contained the Flag-ESC-E $(z)$ complex were pooled and concentrated by precipitation with $75 \%$ saturated ammonium sulfate. The precipitated proteins $(\sim 3 \mathrm{mg})$ were resuspended in $1 \mathrm{~mL}$ of buffer $\mathrm{BC}$ containing $100 \mathrm{mM} \mathrm{KCl}$ and precleared by incubation with protein A agarose beads (100 $\mu \mathrm{L}$ bed volume, Repligen). The precleared pool was incubated with anti-Flag M2 agarose (100 $\mu \mathrm{L}$ bed volume, Kodak). The bound proteins were washed three times with buffer $\mathrm{BC}$ containing $350 \mathrm{mM} \mathrm{KCl}$ and eluted with $200 \mu \mathrm{L}$ of buffer A $\left(50 \mathrm{mM}\right.$ Tris- $\mathrm{HCl}$ at $\mathrm{pH} 7.9$ and $4^{\circ} \mathrm{C}, 100$ $\mathrm{mM} \mathrm{KCl}, 0.2 \mathrm{mM}$ EDTA, $10 \mathrm{mM}$ 2-mercaptoethanol, $0.2 \mathrm{mM}$ phenylmethylsulfonyl fluoride) containing $0.2 \mathrm{mg} / \mathrm{mL}$ Flag peptide (Kodak). For storage, eluted proteins were dialyzed against buffer A containing 30\% glycerol.

\section{HMT assays}

HMT assays were performed essentially as described (Nishioka et al. 2002a). Briefly, the M2 agarose eluates or column fractions were incubated at $30^{\circ} \mathrm{C}$ for different time periods, as indicated on the figures, with $2 \mu \mathrm{g}$ of recombinant or native histone octamer, oligonucleosome, or GST-H3 tail fusion protein (Tachibana et al. 2001) in a buffer containing $50 \mathrm{mM}$ Tris- $\mathrm{HCl}$ (pH 8.5), $5 \mathrm{mM} \mathrm{MgCl}_{2}, 4 \mathrm{mM}$ DTT, and $1 \mu \mathrm{M}{ }^{3} \mathrm{H}$-labeled $S$ adenosyl methionine (Amersham Pharmacia Biotech). Reactions were stopped by adding SDS-PAGE sample buffer, and the reaction products were separated on an SDS $12.5 \%$ polyacrylamide gel. The proteins were transferred to an Immobilon-P membrane (Millipore), and the membrane was either exposed to a tritium phosphorimager screen or autoradiographed.

Native octamer and oligonucleosomes were purified from HeLa cells as previously described (Orphanides et al. 1998). Octamers and oligonucleosomes with recombinant Xenopus histones were prepared as described by Luger et al. (1999). Plasmid containing 5S ribosomal DNA repeats was used for assembly of oligonucleosomes.

\section{Conventional chromatography}

HeLa-derived nuclear extracts were prepared as described previously (Nishioka et al. 2002a). All procedures were performed at $4^{\circ} \mathrm{C}$. Approximately $16 \mathrm{~g}$ of proteins derived from the nuclear pellet fraction were loaded onto a 1500-mL DEAE-52 (Whatman) column equilibrated with buffer C (50 mM Tris- $\mathrm{HCl}$ at $\mathrm{pH}$ 7.9, $0.2 \mathrm{mM}$ EDTA, 10\% glycerol, $1 \mathrm{mM}$ DTT, $0.2 \mathrm{mM}$ PMSF) containing $0.1 \mathrm{M}$ ammonium sulfate. The column was eluted with a $5 \mathrm{~L}$ linear gradient of ammonium sulfate from 0.1 to 0.5 $\mathrm{M}$ in buffer $\mathrm{C}$. The $\mathrm{E}(\mathrm{z})$-containing fractions were dialyzed against buffer $\mathrm{C}$ containing $50 \mathrm{mM}$ ammonium sulfate and loaded on a 200-mL phosphocellulose column (Sigma). The column was eluted with a $2 \mathrm{~L}$ gradient of ammonium sulfate from 50 to $500 \mathrm{mM}$ in buffer $\mathrm{C}$. The $\mathrm{E}(\mathrm{z})$-containing fractions were dialyzed against buffer $\mathrm{BC}(10 \%$ glycerol, $50 \mathrm{mM}$ Tris- $\mathrm{HCl}$ at $\mathrm{pH}$ 7.9 and $4^{\circ} \mathrm{C}, 0.2 \mathrm{mM}$ EDTA, $10 \mathrm{mM}$ 2-mercaptoethanol, $0.2 \mathrm{mM}$ phenylmethylsulfonyl fluoride) containing $50 \mathrm{mM}$ ammonium sulfate and loaded on a 35-mL DEAE-5PW column (TosoHaas). The column was eluted with a 500-mL linear gradient of ammonium sulfate from 50 to $500 \mathrm{mM}$. The $\mathrm{E}(\mathrm{z})$-containing fractions were pooled and concentrated by precipitation with $65 \%$ - saturated ammonium sulfate. The sample was loaded onto a 120-mL Superose 6 column (Amersham Pharmacia Biotech) equilibrated in buffer $\mathrm{BC}$ containing $0.5 \mathrm{M} \mathrm{KCl}$. The activity eluted in the range of $\sim 400$ to $500 \mathrm{kD}$. The active fractions were dialyzed against buffer $\mathrm{BC}$ containing $1 \mathrm{M}$ ammonium sulfate and loaded onto a $1 \mathrm{~mL}$ phenyl-Superose column (Amersham Pharmacia Biotech). The column was eluted with a 10-mL linear gradient of ammonium sulfate from $1 \mathrm{M}$ to $0 \mathrm{M}$ in buffer $\mathrm{BC}$. The active fractions were dialyzed against buffer $\mathrm{BC}$ containing $100 \mathrm{mM} \mathrm{KCl}$ and loaded on a $100-\mu \mathrm{L}$ SMART-MonoP column (Amersham Pharmacia Biotech). The column was eluted with a 1 -mL linear gradient of $\mathrm{KCl}$ from $100 \mathrm{mM}$ to $1 \mathrm{M}$. The active fractions were dialyzed against buffer $\mathrm{BC}$ containing $50 \mathrm{mM}$ $\mathrm{KCl}$ and loaded onto a 100- $\mu \mathrm{L}$ SMART-MonoQ column (Amersham Pharmacia Biotech). The column was eluted with a $1-\mathrm{mL}$ linear gradient of $\mathrm{KCl}$ from 50 to $500 \mathrm{mM}$ in buffer BC. The active fractions were pooled and the pool was fractionated on a 2.4-mL SMART-Superose 12 column (Amersham Pharmacia Biotech).

\section{Plasmid construction and transient transfections}

cDNAs encoding the mouse homolog of $E(z)$ (Enx1) and the human homolog of ESC (hEED) were a gift from Dr. A.P. Otte (University of Amsterdam, Amsterdam, The Netherlands). The H689A mutant was generated using the Quick Change SiteDirected Mutagenesis Kit (Stratagene). The IMAGE clone, which contained a full-length cDNA of the human homolog of $\mathrm{Su}(z) 12$, was purchased from Research Genetics. For subcloning into the pCMV-Flag-4 mammalian expression vector, ESC, $E(z)$, and $\mathrm{Su}(z) 12$ ORFs were amplified using primers that contained adaptors for EcoRI and BamHI (ESC), KpnI and XbaI [E(z)], or $E c o R I$ and $X b a I[S u(z) 12]$. The PCR products were digested with the corresponding restriction enzymes and ligated into the pCMV-Flag-4 expression vector that had been linearized with the same enzymes.

For transient transfections, 293 cells were plated in $10-\mathrm{cm}$ dishes at $10^{7}$ cells per dish the day before transfection. Cells were transfected with $5 \mu \mathrm{g}$ of plasmid DNA using the calcium phosphate precipitation procedure. At day 2 posttransfection, cells were harvested and processed for preparation of nuclear extracts as described above. For immunoprecipitation, $1 \mathrm{mg}$ of the nuclear extract was dialyzed against buffer B containing 100 $\mathrm{mM} \mathrm{KCl}$, precleared with protein A agarose $(100 \mu \mathrm{L}$ bed volume), and incubated with anti-Flag M2 agarose $(20 \mu \mathrm{L}$ bed volume). Bound proteins were washed with buffer B containing 350 $\mathrm{mM} \mathrm{KCl}$ and eluted with buffer B containing $100 \mathrm{mM} \mathrm{KCl}$ and $0.2 \mathrm{mg} / \mathrm{mL}$ Flag peptide for HMT assays or with $0.1 \mathrm{M}$ glycine (pH 2.6) for Western blots.

\section{Protein identification}

Proteins were separated on SDS-polyacrylamide gels, and the protein bands were excised and digested with trypsin. The digested protein mixtures were then fractionated on a Poros 50 R2 RP microtip (Erdjument-Bromage et al. 1998). The resulting peptide pools were analyzed by MALDI-reTOF MS using a Reflex III instrument (Bruker Daltonics) and by ESI MS/MS on an API 300 triple quadrupole instrument (ABI/MDS SCIEX; Thornhill) modified with an ultrafine ionization source (Geromanos et al. 2000). Selected mass values from the MALDI-TOF experiments were used to search the protein nonredundant database $\left(\mathrm{NR}_{\text {; }}\right.$ National Center for Biotechnology Information) using the PeptideSearch algorithm (Mann et al. 1993). MS/MS spectra from ESI triple quadrupole analyses were inspected for the " $y$ " ion series, and the resultant information was transferred to the Pep- 
Frag program (Fenyö et al. 1998) and used as a search string. Peptide identifications that were thus obtained were verified by comparing the computer-generated fragment ion series of the predicted tryptic peptide with the experimental MS/MS data.

\section{Peptide binding assay}

The following peptides were synthesized: H3-tri-methyl-K4 [ART$\mathrm{K}(\mathrm{Me})_{3} \mathrm{QTARC}$ ], H3-tri-methyl-K9 [KQTAR-K(Me) ${ }_{3}$ STGGKC], H3tri-methyl-K27 [TKAAR-K(Me) ${ }_{3}$ SAPC], H3(4-32) (KQTARKSTGG KAPRKQLATKAARKSAPATC), and H3-tri-methyl-K9/tri-methylK27 [KQTAR-K(Me) ${ }_{3}$ STGGKAPRKQLATKAAR-K(Me) ${ }_{3}$-SAPATC]. The peptides were coupled to SulfoLink gel (Pierce) through a Cterminal cysteine according to the manufacturer's instructions. The recombinant $\mathrm{HP} 1$ and $\mathrm{PC} 1$ (rHP1 and $\mathrm{rPC} 1$ ) proteins were obtained by in vitro translation using $1 \mu \mathrm{g}$ of $\mathrm{CMV}($ myc) $3 \mathrm{M} 33$ and CMV(myc)3 HP1 $\beta$ vectors (Lachner et al. 2001) in a $50 \mu \mathrm{L}$ in vitro translation reaction using the TNT in vitro translation kit (Promega). For pull-down assays, $10 \mu \mathrm{L}$ (bed volume) of peptide beads were incubated with $5 \mu \mathrm{L}$ of in vitro translation reaction for $2 \mathrm{~h}$ in presence or absence of $10 \%$ BSA. The beads were washed five times vigorously with buffer $\mathrm{C}$ containing $150 \mathrm{mM} \mathrm{KCl}$ and $0.1 \%$ Triton X-100 for rPC1, with buffer C containing $500 \mathrm{mM} \mathrm{KCl}$ and $0.1 \%$ Triton X-100 for $\mathrm{rHP} 1$. The bound proteins were eluted with SDS-PAGE loading buffer and resolved on a 10\% SDS-polyacrylamide gel. The gel was dried and autoradiographed.

\section{Radiolabeled histone sequencing}

Native HeLa histones were labeled with ${ }^{3} \mathrm{H}$-SAM using conventionally purified enzyme and fractionated on a $15 \%$ SDS-polyacrylamide gel. The $\mathrm{H} 3$ polypeptide was then transferred onto an Immobilon-P membrane and subjected to Edman degradation amino acid analysis coupled with scintillation counting.

\section{Acknowledgments}

We thank Dr. A.P. Otte (University of Amsterdam, Amsterdam, The Netherlands) for the gift of hEED and Enx1 cDNA, as well as anti-hEED and anti-Enxl antibodies. We also thank Dr. T. Jenuwein for the gift of $\mathrm{HP} 1$ and $\mathrm{mPC} 1$ in vitro translation vectors, Dr. Shinkai for the gift of GST-H3 tail expression vectors, and Dr. Neil Brockdorff for communicating unpublished results. We thank Dr. Lynne Vales for comments on the manuscript and Sergei Chuikov and Kavitha Sarma for discussions and help with HMT assays. This work was supported by grants from NIH (GM-37120) and the Howard Hughes Medical Institute to D.R, and by an NCI Cancer Center Support Grant P30 CA08748 to P.T.

The publication costs of this article were defrayed in part by payment of page charges. This article must therefore be hereby marked "advertisement" in accordance with 18 USC section 1734 solely to indicate this fact.

\section{References}

Bajusz, I., Sipos, L., Gyorgypal, Z., Carrington, E.A., Jones, R.S., Gausz, J., and Gyurkovics, H. 2001. The Trithorax-mimic allele of Enhancer of zeste renders active domains of target genes accessible to Polycomb-group-dependent silencing in Drosophila melanogaster. Genetics 159: 1135-1150.

Beuchle, D., Struhl, G., and Muller, J. 2001. Polycomb group proteins and heritable silencing of Drosophila Hox genes. Development 128: 993-1004.

Birve, A., Sengupta, A.K., Beuchle, D., Larsson, J., Kennison, J.A., Rasmuson-Lestander, A., and Muller, J. 2001. Su(z)12, a novel Drosophila Polycomb group gene that is conserved in vertebrates and plants. Development 128: 3371-3379.

Briggs, S.D., Bryk, M., Strahl, B.D., Cheung, W.L., Davie, J.K., Dent, S.Y., Winston, F., and Allis, C.D. 2001. Histone H3 lysine 4 methylation is mediated by Set1 and required for cell growth and rDNA silencing in Saccharomyces cerevisiae. Genes \& Dev. 15: 3286-3295.

Carrington,. E.A. and Jones, R.S. 1996. The Drosophila Enhancer of zeste gene encodes a chromosomal protein: examination of wild-type and mutant protein distribution. Development 122: 4073-4083.

Dignam, J.D., Lebovitz, R.M., and Roeder, R.G. 1983. Accurate transcription initiation by RNA polymerase II in a soluble extract from isolated mammalian nuclei. Nucleic Acids Res. 11: 1475-1489.

Erdjument-Bromage, H., Lui, M., Lacomis, L., Grewal, A., Annan, R.S., McNulty, D.E., Carr, S.A., and Tempst, P. 1998. Examination of micro-tip reversed-phase liquid chromatographic extraction of peptide pools for mass spectrometric analysis. J. Chromatogr. A 826: 167-181.

Fenyö, D., Qin, J., and Chait, B.T. 1998. Protein identification using mass spectrometric information. Electrophoresis 19: 998-1005.

Geromanos, S., Freckleton, G., and Tempst, P. 2000. Tuning of an electrospray ionization source for maximum peptide-ion transmission into a mass spectrometer. Anal. Chem. 72: $777-790$.

Jacobs, J.J. and van Lohuizen, M. 1999. Cellular memory of transcriptional states by Polycomb-group proteins. Semin. Cell. Dev. Biol. 10: 227-235.

Kehle, J., Beuchle, D., Treuheit, S., Christen, B., Kennison, J.A., Bienz, M., and Muller, J. 1998. dMi-2, a hunchback-interacting protein that functions in Polycomb repression. Science 282: $1897-1900$.

Koontz, J.I., Soreng, A.L., Nucci, M., Kuo, F.C., Pauwels, P., van Den Berghe, H., Cin, P.D., Fletcher, J.A., and Sklar, J. 2001. Frequent fusion of the JAZF1 and JJAZ1 genes in endometrial stromal tumors. Proc. Natl. Acad. Sci. 98: 6348-6353.

Lachner, M., O'Carroll, D., Rea, S., Mechtler, K., and Jenuwein, T. 2001. Methylation of histone $\mathrm{H} 3$ lysine 9 creates a binding site for HP1 proteins. Nature 410: 116-120.

Laible, G., Wolf, A., Dorn, R., Reuter, G., Nislow, C., Lebersorger, A., Popkin, D., Pillus, L., and Jenuwein, T. 1997. Mammalian homologues of the Polycomb-group gene Enhancer of zeste mediate gene silencing in Drosophila heterochromatin and at $S$. cerevisiae telomeres. EMBO J. 16: 32193232 .

Luger, K., Rechsteiner, T.J., and Richmond, T.J. 1999. Preparation of nucleosome core particle from recombinant histones. Methods Enzymol. 304: 3-19.

Luo, M., Bilodeau, P., Koltunow, A., Dennis, E.S., Peacock, W.J., and Chaudhury, A.M. 1999. Genes controlling fertilizationindependent seed development in Arabidopsis thaliana. Proc. Nat1. Acad. Sci. 96: 296-301.

Mak, W., Baxter, J., Silva, J., Newall, A.E., Otte, A.P., and Brockdorff, N. 2002. Mitotically stable association of Polycomb group proteins eed and enxl with the inactive X-chromosome in trophoblast stem cells. Curr. Biol. 12: 1016-1020.

Mann, M., Hojrup, P., and Roepstorff, P. 1993. Use of mass spectrometric molecular weight information to identify proteins in sequence databases. Biol. Mass Spectrom. 22: 338345.

Nakayama, J., Rice, J.C., Strahl, B.D., Allis, C.D., and Grewal, S.I. 2001. Role of histone H3 lysine 9 methylation in epigenetic control of heterochromatin assembly. Science 292: $110-113$. 
Ng, J., Hart, C.M., Morgan, K., and Simon, J.A. 2000. A Drosophila ESC-E(Z) protein complex is distinct from other polycomb group complexes and contains covalently modified ESC. Mol. Cell Biol. 20: 3069-3078.

Nishioka, K., Chuikov, S., Sarma, K., Erdjument-Bromage, H., Allis, C.D., Tempst, P., and Reinberg, D. 2002a. Set9, a novel histone $\mathrm{H} 3$ methyltransferase that facilitates transcription by precluding histone tail modifications required for heterochromatin formation. Genes \& Dev. 16: 479-489.

Nishioka, K., Rice, J.C., Sarma, K., Erdjument-Bromage, H., Werner, J., Wang, Y., Chuikov, S., Valenzuela, P., Tempst, P., Steward, R., et al. 2002b. PR-Set7 is a nucleosome-specific methyltransferase that modifies lysine 20 of histone $\mathrm{H} 4$ and is associated with silent chromatin. Mol. Cell 9: 1201-1213.

Orphanides, G., LeRoy, G., Chang, C.H., Luse, D.S., and Reinberg, D. 1998. FACT: A factor that facilitates transcript elongation through nucleosomes. Cell 92: 105-116.

Peters, A.H., Mermoud, J.E., O'Carroll, D., Pagani, M., Schweizer, D., Brockdorff, N., and Jenuwein, T. 2002. Histone H3 lysine 9 methylation is an epigenetic imprint of facultative heterochromatin. Nat. Genet. 30: 77-80.

Platero, J.S., Sharp, E.J., Adler, P.N., and Eissenberg, J.C. 1996. In vivo assay for protein-protein interactions using Drosophila chromosomes. Chromosoma 104: 393-404.

Rastelli, L., Chan, C.S., and Pirrotta, V. 1993. Related chromosome binding sites for zeste, suppressors of zeste and Polycomb group proteins in Drosophila and their dependence on Enhancer of zeste function. EMBO J. 12: 1513-1522.

Rea, S., Eisenhaber, F., O'Carroll, D., Strahl, B.D., Sun, Z.W., Schmid, M., Opravil, S., Mechtler, K., Ponting, C.P., Allis, C.D., et al. 2000. Regulation of chromatin structure by sitespecific histone H3 methyltransferases. Nature 406: 593599.

Sewalt, R.G., van der Vlag, J., Gunster, M.J., Hamer, K.M., den Blaauwen, J.L., Satijn, D.P.E., Hendrix, T., van Driel, R., and Otte, A.P. 1998. Characterization of interactions between the mammalian Polycomb-group proteins Enx1/EZH2 and EED suggests the existence of different mammalian Polycomb-group protein complexes. Mol. Cell. Biol. 18: 35863595.

Sewalt, R.G., Lachner, M., Vargas, M., Hamer, K.M., den Blaauwen, J.L., Hendrix, T., Melcher, M., Schweizer, D., Jenuwein, T., and Otte, A.P. 2002. Selective interactions between vertebrate Polycomb homologs and the SUV39H1 histone lysine methyltransferase suggest that histone H3-K9 methylation contributes to chromosomal targeting of Polycomb group proteins. Mol. Cell. Biol. 22: 5539-5553.

Shao, Z., Raible, F., Mollaaghababa, R., Guyon, J.R., Wu, C.T., Bender, W., and Kingston, R.E. 1999. Stabilization of chromatin structure by PRC1, a Polycomb complex. Cell 98: 3746.

Strahl, B.D., Ohba, R., Cook, R.G., and Allis, C.D. 1999. Methylation of histone $\mathrm{H} 3$ at lysine 4 is highly conserved and correlates with transcriptionally active nuclei in Tetrahymena. Proc. Natl. Acad. Sci. 96: 14967-14972.

Strahl, B.D., Grant, P.A., Briggs, S.D., Sun, Z.W., Bone, J.R., Caldwell, J.A., Mollah, S., Cook, R.G., Shabanowitz, J., Hunt, D.F., et al. 2002. Set2 is a nucleosomal histone H3selective methyltransferase that mediates transcriptional repression. Mol. Cell. Biol. 22: 1298-1306.

Tachibana, M., Sugimoto, K., Fukushima, T., and Shinkai, Y. 2001. Set domain-containing protein, G9a, is a novel lysinepreferring mammalian histone methyltransferase with hyperactivity and specific selectivity to lysines 9 and 27 of histone H3. J. Biol. Chem. 276: 25309-25317.

Tachibana, M., Sugimoto, K., Nozaki, M., Ueda, J., Ohta, T.,
Ohki, M., Fukuda, M., Takeda, N., Niida, H., Kato, H, et al. 2002. G9a histone methyltransferase plays a dominant role in euchromatic histone $\mathrm{H} 3$ lysine 9 methylation and is essential for early embryogenesis. Genes \& Dev. 16: 17791791.

Thompson, J.D., Higgins, D.G., and Gibson, T.J. 1994 CLUSTAL W: Improving the sensitivity of progressive multiple sequence alignment through sequence weighting, position-specific gap penalties and weight matrix choice. Nucleic Acids Res. 22: 4673-4680.

Tie, F., Furuyama, T., Prasad-Sinha, J., Jane, E., and Harte, P.J. 2001. The Drosophila Polycomb Group proteins ESC and $\mathrm{E}(\mathrm{Z})$ are present in a complex containing the histone-binding protein 555 and the histone deacetylase RPD3. Development 128: $275-286$.

van der Vlag, J. and Otte, A.P. 1999. Transcriptional repression mediated by the human polycomb-group protein EED involves histone deacetylation. Nat. Genet. 23: 474-478.

Verreault, A., Kaufman, P.D., Kobayashi, R., and Stillman, B. 1998. Nucleosomal DNA regulates the core-histone-binding subunit of the human Hatl acetyltransferase. Curr. Biol. 8: $96-108$.

Wang, H., Cao, R., Xia, L., Erdjument-Bromage, H., Borchers, C., Tempst, P., and Zhang, Y. 2001. Purification and functional characterization of a histone H3-lysine 4-specific methyltransferase. Mol. Cell 8: 1207-1217.

Wang, J., Mager, J., Chen, Y., Schneider, E., Cross, J.C., Nagy, A., and Magnuson T. 2001. Imprinted $\mathrm{X}$ inactivation maintained by a mouse Polycomb group gene. Nat. Genet. 28: 371-375.

Weinmann, A.S., Bartley, S.M., Zhang, T., Zhang, M.Q., and Farnham, P.J. 2001. Use of chromatin immunoprecipitation to clone novel E2F target promoters. Mol. Cell. Biol. 21: 6820-6832.

Yang, L., Xia, L., Wu, D.Y., Wang, H., Chansky, H.A., Schubach, W.H., Hickstein, D.D., and Zhang, Y. 2002. Molecular cloning of ESET, a novel histone H3-specific methyltransferase that interacts with ERG transcription factor. Oncogene 21: $148-152$.

Zhang, Y., LeRoy, G., Seelig, H.P., Lane, W.S., and Reinberg, D. 1998. The dermatomyositis-specific autoantigen Mi2 is a component of a complex containing histone deacetylase and nucleosome remodeling activities. Cell 95: 279-289. 


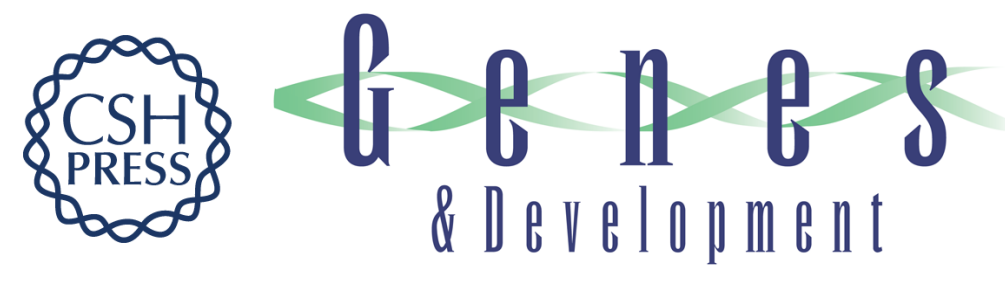

\section{Histone methyltransferase activity associated with a human multiprotein complex containing the Enhancer of Zeste protein}

Andrei Kuzmichev, Kenichi Nishioka, Hediye Erdjument-Bromage, et al.

Genes Dev. 2002, 16:

Access the most recent version at doi:10.1101/gad.1035902

References

This article cites 43 articles, 20 of which can be accessed free at:

http://genesdev.cshlp.org/content/16/22/2893.full.html\#ref-list-1

License

Email Alerting

Receive free email alerts when new articles cite this article - sign up in the box at the top

Service right corner of the article or click here.

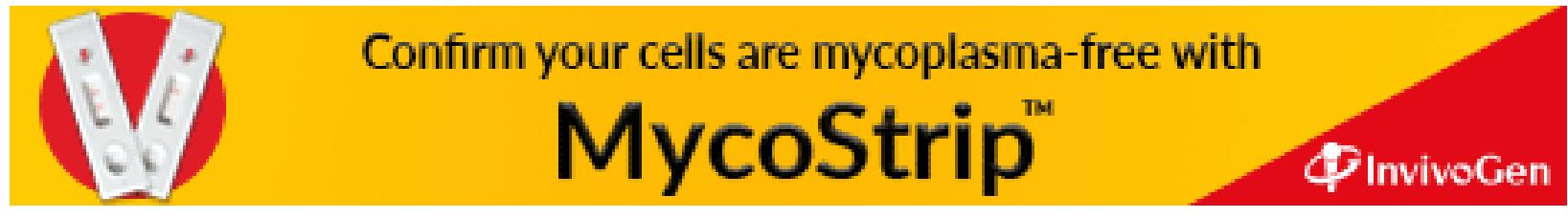

